\title{
FORMAÇÃO DE PROFESSORES, USO DE TECNOLOGIAS DIGITAIS DE INFORMAÇÃO E COMUNICAÇÃO E ESCOLA INCLUSIVA: POSSIBILIDADES DE CONSTRUÇÃO DE UMA ABORDAGEM DE FORMAÇÃO CONSTRUCIONISTA, CONTEXTUALIZADA E SIGNIFICATIVA
}

\author{
Elisa Tomoe Moriya Schlünzen \\ Klaus Schlünzen Junior \\ Danielle Aparecida do Nascimento dos Santos \\ Programa de Pós-Graduação em Educação (FCT/Unesp)
}

Resumo: $\mathrm{O}$ artigo apresenta uma investigação que aborda a formação inicial de professores que já atuam na educação básica/ciclo I. O universo de pesquisa é a disciplina "Eixo Articulador: Educação Inclusiva e Especial" do Curso de Licenciatura em Pedagogia Semi-Presencial proposto pela Universidade Virtual do Estado de São Paulo (Univesp) em parceria com a Universidade Estadual Paulista Júlio de Mesquita Filho (Unesp). A referida disciplina propõe o desenvolvimento de planos de ensino mediados pelo uso de Tecnologias Digitais de Informação e Comunicação (TDIC) em um processo de ensino e aprendizagem que tenha Estudantes Público-Alvo da Educação Especial (EPAEE) incluídos no ambiente escolar. O objetivo é analisar o processo de formação de professores voltado ao ensino dos fundamentos da Educação Inclusiva em uma perspectiva de reforma curricular para trabalhar com projetos usando TDIC em uma abordagem denominada Construcionista, Contextualizada e Significativa (CCS). A natureza metodológica é qualitativa do tipo intervenção, cujos sujeitos da formação semipresencial são professores em exercício e discentes do Curso de Licenciatura em Pedagogia da Univesp/Unesp. O levantamento de dados sinaliza sobre a importância de uma formação contextualizada, que atribua significados aos referenciais teóricos e práticos articulados 
ao dia a dia do professor, e a análise dos resultados poderá caracterizar as contribuições efetivas da proposta de elaboração de planos de ensino inclusivos associados a uma abordagem pedagógica que tem como parâmetro o trabalho com projetos.

Palavras-chave: Formação de Professores. Abordagem Construcionista, Contextualizada e Significativa. Escola Inclusiva.

Abstract: The article presents a research about continuous formating teacher that works at the primary school. The research universe is the discipline "Axis Articulator: Special and Inclusive Education", of virtual Pedagogy course, offered by the Virtual University of São Paulo (UNIVESP) in partnership with the Universidade Estadual Paulista "Júlio de Mesquita Filho" (UNESP). The discipline proposes to develop teaching plans mediated by the use of Information and Communication Technologies (ICT) in a process of teaching and learning with handicapped students included in the schoolar environment. The goal is to analyze the process of teacher's formation aimed at teaching the fundamentals of Inclusive Education in the perspective of curriculum reform to work with ICT on class projects using an approach called constructionist, Contextual and Meaningful. The methodology is qualitative on the intervention type, whose subjects are focused to students-teachers of Pedagogy UNIVESP/ UNESP. The survey data indicates the importance of a contextualized education, which assigns meanings theoretical and practical that are articuleted on the daily life of the teacher, and the analysis of results can characterize the effective contributions of the proposed plans of inclusive education associated a pedagogical approach that has as parameter the project work.

Keywords: Teacher Education. Constructionist, Contextual and Meaningful Approach. Inclusive Education. 


\section{Origem e Fundamentos da Pesquisa}

Esta pesquisa tem origem no grupo de pesquisa Ambientes Potencializadores para a Inclusão (API) da Universidade Estadual Paulista Júlio de Mesquita Filho/Faculdade de Ciências e Tecnologia (Unesp/FCT) que estuda contextos de formação de professores à luz dos eixos temáticos: Uso de Tecnologias Digitais de Informação e Comunicação na Educação (TDIC), Educação Inclusiva e Educação a Distância.

A participação no grupo de pesquisa proporcionou o desenvolvimento de pesquisas de iniciação científica e mestrado $^{1}$ sobre o uso de TDIC para a alfabetização e inclusão digital e social de pessoas com deficiências físicas e intelectuais, e para o trabalho com projetos como fio condutor na formação de professores em serviço de uma escola pública estadual no interior de São Paulo. Nessas duas esferas foi possível descobrir que existem possibilidades de ensinar e aprender valorizando as diferenças mediante o trabalho com projetos e o uso de TDIC, por meio do desenvolvimento de uma abordagem de ensino e de aprendizagem Construcionista, Contextualizada e Significativa (CCS).

A partir do século XXI as mais visíveis e invisíveis mudanças na sociedade demonstram que princípios como: democracia, participação, colaboração e cooperação, solidariedade, inclusão e outros, trazem em seu bojo, além de mudanças no comportamento humano e na forma como este vê e lida com o mundo, mudanças importantes e significativas na concepção do que é conhecimento. O ideal do racionalismo técnico e científico de que, entendendo-se as partes, pode-se entender o todo seguindo uma ordem linear de estudo da natureza e dos seres humanos (ARAÚJO, 2003), dá lugar ao conceito de interacionismo, que torna a humanidade responsável pela 
construção do conhecimento, não mais dividindo partes e isolando os fenômenos, mas em interação com o ambiente, que consequentemente passa a ser visto como relacional, dialógico e mutável (MIZUKAMI et al., 2003).

Com isso, a concepção de construção do conhecimento passa a ser relacionada à interação do sujeito com o meio, com os objetos, com as informações e com o outro, atuando sobre eles, transformando e sendo transformado. Portanto, as reconfigurações nos paradigmas educacional e social emergentes trazem essa concepção de construção do conhecimento como meio de superação de desigualdades e de desenvolvimento pleno do ser humano, em todas as suas dimensões: social, moral, emocional, afetiva, política, física, entre outras.

Tomando como foco a escola, o paradigma educacional emergente $^{2}$ traz para o professor um dos principais agentes escolares, uma gama de situações práticas que envolvem a construção do conhecimento e não mais o domínio do conteúdo. Além disso, demonstra a necessidade da utilização dos mais variados métodos de ensino que possibilitem uma aprendizagem de qualidade para todos, que vai ao encontro do princípio da educação inclusiva: valorizar a diversidade humana.

Por isso, as formas de ensinar são cada vez mais problematizadas, à medida que a escola tenta alcançar um ensino de qualidade, que potencialize o desenvolvimento de habilidades e promova práticas de inclusão escolar voltadas a qualquer público inserido no seu contexto, inclusive os Estudantes Público-Alvo da Educação Especial (EPAEE)3.

De acordo com Zabala (1998), é necessário que a prática pedagógica seja realizada de forma a questionar a ênfase atribuída somente ao aspecto cognitivo da escola. Para ele, é por meio das relações construídas a partir das experiências vividas na escola que podem se estabelecer vínculos e condições que ajudem professores e estudantes a definir as concepções pessoais 
sobre si e sobre os demais, culminando na construção do conhecimento. E é a partir dessa nova posição ideológica sobre os meios e fins da escola que se torna necessária uma reflexão profunda e permanente sobre as reais condições em que se configuram os processos de formação dos professores.

A formação de professores lida com a construção de saberes e conhecimentos docentes. Tardif (2000) caracteriza os saberes docentes como temporais, uma vez que o conhecimento sobre a prática só pode ser construído a partir das experiências construídas, ou seja, do ser e fazer-se professor. Assim, os saberes docentes são construídos dia após dia, na escola, em casa, nas relações que o professor estabelece e por isso, pode-se atribuir um ar de provisoriedade ao conhecimento produzido em formação de professores, posto que as teorias historicamente elaboradas servem como base para a revisão de novas práticas que, por consequência, geram novas teorias e novas práticas.

Portanto, a concepção de formação de professores nesta pesquisa é entendida como um processo de desenvolvimento para a vida, tendo como parâmetro as teorias elaboradas por Knowles, Cole e Presswood (1994), Schön (1983), Pérez Gómez (1992), Imbernón (2000), Zeichner (1993), García (1992), Gatti (2000), entre outros.

Assim, a ideia de processo de formação de professores e, portanto, de continuidade faz com que se pense em estabelecer um fio condutor que produza sentidos e significados às teorias estudadas e às práticas construídas por esse sujeito, garantindo, ao mesmo tempo, que estabeleça conexões entre os saberes construídos na sua formação inicial, com os saberes construídos na prática, não necessariamente científicos, mas voltados às suas necessidades de lidar com a sua prática, com suas condições de trabalho e com seus estudantes. Nesse sentido, a reflexão é vista e entendida como o elemento que promove essas conexões, e como meio para que o professor lide com as suas incertezas, 
com as diferenças entre os estudantes e com a resolução dos problemas práticos vivenciados.

A chamada Escola Inclusiva pode contribuir para que o professor encontre uma necessidade ímpar de resolução de problemas práticos. De acordo com Mantoan (2002), a inclusão escolar faz parte do paradigma educacional emergente, visto que a Constituição de 1988 já assegurava a todas as crianças brasileiras, o direito ao ensino a igualdade de condições de acesso e permanência na escola (art. 206, inciso I), acrescentando que “[...] o dever do Estado com a educação será efetivado mediante a garantia de acesso aos níveis mais elevados do ensino, da pesquisa e da criação artística, segundo a capacidade de cada um." (art. 208, V).

Ainda para Mantoan (2002), a escola se sente ameaçada por tudo o que ela criou para se proteger da vida que existe além de seus muros e paredes porque hoje, certamente, o professor se depara com novos saberes, novos estudantes, com a necessidade de criar novas formas de resolver problemas, e de avaliar o ensino que oferece e a aprendizagem. Assim, as conexões que se formam entre os saberes docentes e os encontros da teoria e da prática com a subjetividade humana, com o cotidiano, o social, o cultural, também apontam a Escola Inclusiva como parte da nova concepção de construção do conhecimento.

Finalmente, outra questão de grande relevância no cenário ora traçado é a inserção de TDIC nas práticas escolares. De acordo com Moran (1998), as TDIC são extensões de nosso corpo, de nossa mente e, portanto, podem ser recursos que potencializam o humano, principalmente se consideradas as necessidades especiais dos EPAEE cujo acesso às informações muitas vezes demanda recursos de acessibilidade. Diante de teóricos que abordam o uso de TDIC na Educação, como Papert (1986), Valente (1991, 1997, 1999), Almeida (2001), Moran, Masetto e Behrens (2000), Moraes (1997, 2003, 2004), Schlünzen (2000), 
Lévy (1993, 2000), entre outros, e a construção de uma Escola Inclusiva, como Mantoan (1997, 2002), Figueiredo (2002), Zardo (2010), entre outros, presentes nas ciências da educação, pode-se considerar que a formação de professores no Brasil ainda carece no que diz respeito à compreensão do uso das tecnologias digitais como recursos de acessibilidade e ludicidade na escola, podendo influenciar diretamente na aprendizagem dos estudantes e na construção de políticas educacionais mais globalizadoras.

Delors (1999) afirma que a escola deve apresentar à criança o mundo real, incluindo as suas complexidades e agitações, indicando caminhos e recursos para percorrer e reconhecer esse mundo em que vivem. Só que essa perspectiva cria uma situação paradoxal, uma vez que o mesmo sistema que preconiza uma sociedade justa, igualitária e inclusiva, infelizmente (pela compreensão das pesquisas em educação de que a formação dos professores ainda é precária nesse sentido), reproduz mecanismos que favorecem a exclusão, dificultando o acesso e a permanência dos EPAEE no ambiente escolar, e limitando as possibilidades de construção do seu próprio conhecimento.

Diante de todos esses princípios, há que se pensar em uma formação de professores para um novo fazer pedagógico, onde seja considerada a multidimensionalidade tanto do professor, quanto dos estudantes. De acordo com Nóvoa (1998), os princípios de formação de professores devem ser voltados à compreensão de suas relações com o saber pedagógico e científico. Portanto, sua formação deve passar pela experimentação, pela inovação, pelo ensaio de novos modos de trabalho pedagógico e por processos de investigação, diretamente articulados com as práticas educativas.

Para tanto, é muito importante que a formação inicial de professores atenda as suas necessidades formativas em todas as dimensões e não somente "capacite-os", quer seja para o 
atendimento aos EPAEE, para o uso de recursos como as TDIC, quer seja para a reprodução de determinadas técnicas de ensino. É necessário que a formação inicial crie um espaço onde sejam consideradas as particularidades e reais singularidades que possam emergir do contexto de atuação dos professores. Para isso, essa formação deve ser dada por meio de um processo de busca, reflexão e análise frente aos saberes acadêmicos e a sua própria prática.

Portanto, a experiência de mais de dez anos vivenciada por pesquisadores da FCT/Unesp, vinculados ao Grupo de Pesquisa API configurada a partir de iniciativas de inclusão digital, escolar e social de EPAEE por meio da formação de professores em serviço, demonstra que uma das alternativas é a reorganização do currículo mediante o trabalho com projetos em uma abordagem denominada Construcionista, Contextualizada e Significativa (CCS) (SCHLÜNZEN, 2000), em que as TDIC podem ser utilizadas como recursos para uma aprendizagem mais autodirigida e inclusiva.

A abordagem CCS tem origem nos estudos de Papert (1986) e Valente (1997), que definiram duas formas de utilização de TDIC no processo de ensino e aprendizagem: Instrucionista e Construcionista, sendo a instrucionista, como o próprio nome sugere, a prática no qual a TDIC é usada como ferramenta para transmitir informações, caracterizando assim a informatização dos métodos tradicionais de ensino; e sendo a construcionista, aquela onde a TDIC é usada como recurso para a resolução de problemas, em que o estudante exerce o papel de quem usa a tecnologia para explicitar suas ideias e produzir o que é de seu interesse. Portanto, o uso da TDIC nessa abordagem permite ao estudante o fácil e rápido acesso a informações que colaboram para explicitar seu pensamento, desenvolver projetos, testar hipóteses e refletir sobre os resultados (SCHLÜNZEN, 2000). A autora utilizou este ponto da abordagem construcionista para a 
elaboração de sua tese considerando que, se professor e estudante tem o controle das operações realizadas usando a tecnologia (uso de um Objeto de Aprendizagem, construção de um blog, pesquisa na internet, comunicação via rede social e outros), podem ter autonomia sobre o processo de ensino e sobre a aprendizagem, intervindo e redefinindo estratégias em parceria.

Com isso, foi criado o ambiente Construcionista, Contextualizado e Significativo ${ }^{5}$ que:

[...] é um ambiente favorável que desperta o interesse do aluno e o motiva a explorar, a pesquisar, a descrever, a refletir, a depurar as suas idéias. É aquele cujo problema nasce de um movimento na sala de aula, no qual os alunos, junto com o professor, decidem desenvolver, com auxílio do computador, um projeto que faz parte da vivência e do contexto dos alunos. No desenvolvimento deste projeto, os alunos irão se deparando com os conceitos das disciplinas curriculares e o professor mediará a sua formalização para que o aluno consiga dar significado ao que está sendo aprendido. (SCHLÜNZEN, 2000, p. 82).

Com isso, pode-se construir uma prática onde as informações sejam manipuladas pelos professores e estudantes, dentro do seu contexto, ou seja, referente à sua vivência social e escolar, sendo atribuídas a essas informações significados que serão transformados em conhecimento. Por isso, o ambiente CCS gerou a abordagem CCS, utilizada como norteadora da prática de formação de professores utilizada na presente pesquisa.

A abordagem CCS de ensino, segundo Schlünzen (2005), possibilita o afloramento do interesse do estudante, motivando-o a explorar, a pesquisar, a descrever, a refletir, a depurar suas ideias, com a mediação do professor, permitindo desenvolver, por meio do uso das TDIC, um projeto que faz parte da sua vivência e contexto. 
Assim, considera-se, diante do estudo elaborado, que a formação de professores para a incorporação das TDIC no ambiente escolar também é pressuposto de um novo paradigma educacional que, necessariamente, demanda da realização de práticas pedagógicas diversificadas que favoreçam a construção do conhecimento por TODOS os estudantes.

\section{O Problema - Cenário da Pesquisa}

De acordo com seu Plano de Desenvolvimento Institucional (PDI), a Universidade Estadual Paulista Júlio de Mesquita Filho (Unesp) empenha-se na formação de professores do ensino fundamental por meio do Programa de Formação para Professores em Exercício, que atuam na educação infantil, nos anos iniciais do ensino fundamental e na gestão de unidade escolar. Assim, em 27 de fevereiro de 2008, firmou Protocolo de Intenções, com a Secretaria do Ensino Superior, para o oferecimento de cursos no Programa Universidade Virtual de Estado de São Paulo (Univesp) ${ }^{6}$, tomando a iniciativa de oferecer curso de nível superior para formação de professores para atuar na Educação Infantil e nos anos iniciais do Ensino Fundamental, sendo esses professores ligados às redes públicas (estadual e municipal) e privada.

Com isso, surgiu o curso de Licenciatura em Pedagogia Univesp/Unesp, que oferece formação atualmente para 1004 (um mil e quatro) professores em exercício na educação básica do Estado de São Paulo. O curso, na modalidade semipresencial está organizado em módulos e temas/disciplinas a partir de grandes áreas de formação em licenciatura. São 27 (vinte e sete) turmas espalhadas em polos vinculados aos campi da Unesp, cada uma delas orientada por dois professores do campus (professores 
doutores da Unesp) e dois orientadores de disciplina (tutores presenciais), contratados por regime CLT. As disciplinas são elaboradas por professores especialistas (também vinculados à universidade) e assistentes e são organizadas em três blocos, sendo o primeiro de Formação Geral, o segundo de Didática dos Conteúdos e o terceiro de Gestão Escolar. Cada bloco é organizado por temas e disciplinas e os módulos incluídos nos blocos são interligados por Eixos Articuladores? .

Desse modo, o Eixo Articulador: Educação Inclusiva e Especial - $120 \mathrm{~h} / \mathrm{a}$ (vinculado ao Bloco 2: Didática dos Conteúdos) foi elaborado com base no Projeto Político Pedagógico do Curso de Licenciatura em Pedagogia Unesp/ Univesp (2008), que considera que, além do conhecimento específico de sua área ou nível de atuação, os professores devem conhecer e refletir sobre os recursos pedagógicos e tecnológicos necessários para que sejam capazes de desenvolver um trabalho pedagógico que ofereça às crianças as condições necessárias para que elas possam construir um mundo orientado pela solidariedade e respeito às diferenças.

Além disso, por se tratar de um programa de formação continuada de professores semipresencial, a proposta do curso tem como premissa a utilização de recursos tecnológicos para difusão, otimização e geração do saber científico e também como elementos de uma proposta inovadora, que visa aplicar diversas possibilidades de uso desses recursos para que os professores os utilizem de fato no ambiente escolar.

Assim, a problemática da pesquisa ora retratada apresentou-se por meio da elaboração e acompanhamento do desenvolvimento do Eixo Articulador: Educação Inclusiva e Especial, considerando a necessária formação inicial de professores que atenda aos pressupostos da Escola Inclusiva e que nos ajude a compreender quais práticas de formação são necessárias para que os métodos e técnicas de ensino e as inovações tecnológicas 
não sejam reduzidas a uma formação realizada em espaços de transmissão passiva de saberes.

Por esses motivos, a pesquisa tem como pressuposto a formação inicial de professores do curso de Licenciatura em Pedagogia Univesp/Unesp, que já atuam no ensino básico, pressupondo que, ao desenvolver as atividades do Eixo Articulador, os professores podem construir uma escola inclusiva mediante o uso de TDIC, além de uma análise do currículo escolar para o desenvolvimento de uma abordagem CCS.

Atentando à premissa de que para que se abra a possibilidade ensino de qualidade, reforma educativa, inovação pedagógica com uma formação inicial de professores que atenda aos preceitos de sua prática pedagógica, as perguntas da pesquisa são:

1. É possível, no processo de formação de professores em um curso de Licenciatura em Pedagogia semipresencial, orientá-los para trabalhar em uma abordagem CCS, para a construção de uma escola inclusiva?

2. O que o Eixo Articulador: Educação Inclusiva e Especial acrescenta no sentido de o professor conseguir aplicar os conhecimentos construídos no seu contexto?

3. De que forma essa formação faz com que o professor compreenda como incluir?

Tendo delineados a problemática/problema, perguntas e objeto de pesquisa, o objetivo geral da pesquisa é analisar o processo de formação inicial de professores voltado ao ensino dos fundamentos da educação inclusiva em uma perspectiva de reforma curricular para trabalhar com projetos usando TDIC em uma abordagem CCS. 


\section{Delineamento Metodológico}

Diante do objetivo geral, a pesquisa propõe como eixos específicos: a análise do currículo de formação inicial do curso de Licenciatura em Pedagogia Univesp/Unesp com relação ao Eixo Articulador que aborda o uso de TDIC e o Trabalho com Projetos segundo uma abordagem CCS e Inclusiva; a análise do processo de elaboração, execução e avaliação do Eixo Articulador; a verificação das estratégias de ensino criadas pelos professores em formação mediante os conhecimentos construídos no Eixo e, finalmente; a identificação dos princípios que podem nortear a prática pedagógica de professores considerando os pontos necessários a uma prática CCS. Atualmente em fase de coleta e seleção dos dados, as ações de estudo teórico e a submissão ao Comitê de Ética em Pesquisa ${ }^{8}$ já foram organizados.

A natureza da pesquisa é aplicada e a abordagem do problema qualitativa. De acordo com Deslandes et al. (1994) a pesquisa qualitativa trabalha com o universo de significados, motivos, aspirações, crenças, valores e atitudes, lidando com um espaço profundo de relações, processos e fenômenos que não podem ser reduzidos à operacionalização de variáveis.

Além disso, a pesquisa é caracterizada pelo tipo intervenção, sendo mediada por propostas de atuação transformadora da realidade sócio-política, já que propõe uma intervenção de ordem micropolítica na experiência social (STENGERS, 1990).

Nesse sentido, tendo como universo de pesquisa, o Eixo Articulador: Educação Especial e Inclusiva do curso de Licenciatura em Pedagogia da Univesp/Unesp, foram delimitados, como focos de coleta, seleção e análise de dados, três turmas (Araçatuba, Assis e São José do Rio Preto.

Durante os anos de 2011 e 2012 encontraram-se em andamento a elaboração e implementação de atividades de 
formação do Eixo Articulador. A intervenção foi caracterizada: pela elaboração do plano de ensino da disciplina, seleção dos conteúdos a serem desenvolvidos, procedimentos de ensino e avaliação, formação dos orientadores de turma e de disciplina, e posterior seleção dos sujeitos para uma análise mais aprofundada dos elementos práticos da disciplina que estão sendo utilizados em seu contexto de atuação.

\section{Desenvolvimento da Pesquisa: pressupostos da elaboração do Eixo Articulador}

O Eixo Articulador Educação Inclusiva e Especial constitui 120 horas (cento e vinte horas) que foram distribuídas em cinco blocos de $24 \mathrm{~h} / \mathrm{a}$ (vinte e quatro horas aula) semanais em encontros presenciais e momentos virtuais. Essas atividades foram realizadas entre as disciplinas de Conteúdos: Didática Geral, Didática de Alfabetização, Didática de Língua Portuguesa e Literatura, Didática de Artes, Didática de Educação Física, Didática de Matemática, Didática de História, Didática de Geografia, Didática de Ciências e Saúde e, para articular ao próprio eixo, Didática de Libras ${ }^{9}$ (Língua Brasileira de Sinais).

A elaboração do Eixo Articulador foi pensada diante da expectativa de elencar os conhecimentos sobre o histórico da Inclusão Escolar e da Educação Especial no Brasil e no mundo, considerando suas características, diferenças, semelhanças, políticas de ação e possibilidades de atuação profissional. Para de fato articular o eixo às disciplinas didática dos conteúdos, sua elaboração teve início no ano de 2009, considerando a necessidade de apresentação dos seus conteúdos sob a forma de blocos representativos de cada característica abrangida pelas áreas das didáticas. 
Assim, foram definidos os blocos de conteúdo do Eixo Articulador:

1) Política de Educação Inclusiva e Adaptações Curriculares;

2) Trabalho com Projetos e Apresentação de TDIC e Objetos Educacionais;

3) TDIC para o trabalho com conteúdos específicos das Didáticas de Conteúdo;

4) Elaboração e aplicação de Planos de Ensino Inclusivos (PEI)

e Projetos articulados aos diferentes conteúdos das Didáticas de Conteúdo.

Tendo como base a realização de atividades presenciais e a distância no AVA TelEduc, situado no portal Edutec ${ }^{10}$, bem como a distribuição semanal entre as disciplinas de Didáticas de Conteúdo, a dinâmica metodológica do Eixo Articulador foi organizada no sentido de integrar teoria e prática, a partir de leituras, sínteses e discussão dos textos solicitados; levantamento e vivência de atividades propostas por diferentes fontes, inclusive a valorização de experiências construídas pelos estudantes/ professores; realização de pesquisas junto às instituições de ensino para que os estudantes tenham contato com a realidade e possam preparar-se para o trabalho pedagógico; uso das ferramentas da plataforma de aprendizagem virtual; organização e desenvolvimento de trabalhos em grupo (PEI); e compreensão e domínio do conteúdo trabalhado.

A primeira parte do Eixo foi organizada com o sentido de apresentar os conteúdos e conceitos-chave para compreensão do seu tema, articulado ao conhecimento construído na disciplina de Didática Geral. Foram organizadas atividades para iniciar a elaboração coletiva de um PEI tendo por base os conteúdos estudados ao longo da disciplina Didática Geral. Assim, os professores foram estimulados a aproveitar os conhecimentos construídos nessa disciplina para a organização de um PEI, 
baseado em um roteiro específico. Essa atividade, vinculada a outras atividades de: diálogo participativo, leitura de textos, apresentação das Políticas Educacionais (Marcos Legais) e resolução de um questionário, se fundamentou na articulação das ideias frente às realidades distintas, apresentadas por cada membro dos grupos formados, considerando a área de atuação profissional.

Desde esse primeiro momento foi necessário esclarecer que o foco da atividade prática deveria ser os estudantes com os quais atuavam, as suas necessidades e seu contexto. Além disso, a orientação inicial era de que pudessem articular seus conhecimentos específicos para a elaboração de um plano de ensino que atendesse às diferenças entre os seus estudantes, ainda que não fossem público-alvo da Educação Especial. Desde essa primeira etapa foi proposta a construção do conhecimento na ação, manifestado no saber fazer e fruto da experiência e da reflexão sobre a mesma (PÉREZ GÓMEZ, 1992).

$\mathrm{Na}$ segunda parte, que foi proposta logo após a Disciplina de Conteúdos de Didática de Alfabetização, as atividades e materiais foram organizados prevendo a aplicação dos conceitos aprendidos sobre Alfabetização, pressupondo o trabalho individual e coletivo entre os estudantes, tanto nos encontros presenciais, quanto no AVA. Adicionalmente, foi proposto um debate que tratou especificamente da elaboração do PEI, iniciado na primeira semana. De acordo com Zeichner (1993), a prática reflexiva ocorre quando é proposta uma consideração ativa, persistente e cuidadosa daquilo em que se acredita ou se pratica. Portanto, a intenção, na segunda semana do Eixo, era articular os PEI já elaborados para uma apresentação coletiva e presencial.

Essa estratégia permitiu que os professores tivessem a oportunidade de desenvolver ainda melhor a capacidade de planejar, selecionar e aplicar, no contexto escolar e na sala de aula, os recursos pedagógicos e tecnológicos com 
vistas ao atendimento dos EPAEE. Para avaliar a motivação e aprendizagem gerada por essa estratégia, ainda nesta parte foi proposto o Memorial Reflexivo, em que os professores realizaram uma autoavaliação de todo o percurso (processo) vivido ao longo do Eixo.

Considera-se nessa etapa que empregar a reflexão por meio de um memorial não significaria que os professores estariam refletindo sobre tudo, mas que deveriam buscar o equilíbrio entre a sua reflexão e a sua vivência, entre ato e pensamento, podendo decidir conscientemente o caminho a seguir (MIZUKAMI et al., 2003).

Portanto, nesse momento puderam voltar às suas anotações, em especial as atividades desenvolvidas; os estudos dos textos e vídeos; a interação com os colegas e com o Orientador de Disciplina; os PEI. O roteiro do Memorial considerou perguntas que os levassem a refletir como pessoa e profissional, visando estimular um processo reflexivo no decorrer do eixo.

Na terceira parte as atividades foram elaboradas para oferecer fundamentos para o uso de estratégias e recursos voltados à construção e implementação de práticas de ensino inclusivas, articulando-os aos conteúdos trabalhados nas disciplinas de Conteúdos e Didática de Língua Portuguesa e Literatura e Artes.

Nesse momento foi introduzida a perspectiva e análise de uso das TDIC no processo inclusivo. Os discentes conheceram um Objeto Educacional (OE) "Scrapbook"1 e tiveram a oportunidade de explorar esse objeto em uma aula presencial, visando identificar possibilidades para seu uso no processo de ensino e aprendizagem de conteúdos escolares relacionados aos componentes curriculares de Língua Portuguesa, Literatura e Artes.

Com isso, as TDIC foram inseridas no processo de formação no sentido de atribuir elementos de alta qualidade no qual os professores puderam também interagir com seus 
estudantes, criando estratégias de organização de informações usando hipertexto e hipermídia, oferecendo assim opções de aprendizado mais eficientes (DODGE, 1995).

Assim, além do uso de um OE, tiveram a oportunidade de conhecer e utilizar o Portal do Professor (portal educacional do Ministério da Educação), onde pesquisaram recursos e estratégias pedagógicas disponíveis para o ensino dos conteúdos escolhidos e já inseridos nos PEI coletivos. Além desse portal educacional, foram sugeridas outras fontes de pesquisa e o produto final desta parte do Eixo foi a articulação dos conteúdos trabalhados, com base nas reflexões feitas durante o período virtual anterior, em que os professores voltaram ao PEI e acrescentaram os elementos pesquisados e utilizados nesse momento. Portanto, da concepção do mundo como um fluxo universal de eventos e processos em blocos fixos e imutáveis, passou-se a uma concepção de construção do conhecimento em rede (MORAES, 1997) para uma formação emergente de redes cada vez mais complexas de relações, geradas pela velocidade das comunicações e informações.

A quarta parte do Eixo visou subsidiar o andamento do desenvolvimento dos PEI que foram elaborados ao longo das semanas anteriores. Nas atividades propostas, as estratégias e os recursos conhecidos nas atividades anteriores foram articulados aos conteúdos propostos pelas disciplinas Conteúdo e Didática de Educação Física e Matemática. O contato e uso de outros OE na construção e aplicação dos PEI foi proposto novamente, fundamentando a articulação das ideias de uso desses recursos frente às realidades distintas, apresentadas por cada membro dos grupos já formados desde a primeira semana, considerando sua área de atuação profissional.

Nesse momento, foi realizada uma orientação de que o foco é a aprendizagem do estudante, o desenvolvimento do seu potencial e suas habilidades, dentro do seu contexto. Também foi 
proposta a análise de um vídeo sobre um projeto de AEE junto a estudantes com altas habilidades/superdotação, sinalizando para a reflexão sobre as necessidades específicas desses EPAEE, visto que na parte anterior haviam analisado os EPAEE com transtornos globais de desenvolvimento. De acordo com Mantoan (2002), os sistemas escolares ainda estão montados a partir de um pensamento que recorta a realidade, que permite subdividir os estudantes em "normais" e com deficiência. Portanto, é necessário romper com essa lógica de organização que é marcada por uma visão reducionista própria do pensamento científico moderno, e passar a considerar o subjetivo, o afetivo, o criador e a compreensão das especificidades dos EPAEE que podem ser uma das grandes descobertas dos professores no processo de formação, para que se voltem à construção de sua própria identidade.

Todos esses elementos favoreceram com que os professores articulassem os conhecimentos e as experiências para a elaboração de um PEI que valorizasse a diversidade humana dos estudantes e, finalmente, executassem a sua aplicação na prática.

Finalmente, a quinta parte do Eixo foi realizada em outubro de 2012, após as disciplinas de Conteúdos de Didática de História, Geografia e Ciências e Saúde. Nas atividades foram esclarecidos os elementos de criação desse espaço de análise sobre elaboração e aplicação dos PEI realizados ao longo do Eixo e a primeira atividade proposta foi o compartilhamento dos resultados da aplicação prática dos PEI em sua sala de aula ou escola. Aqui fazse um adendo a uma faceta importante da organização escolar: a autonomia dos professores enquanto agentes e protagonistas de um trabalho com a coletividade, tendo como consequência a transformação das suas ações em interações com um grupo (TARDIF; LESSARD, 2005).

Nesse momento os professores tiveram que destacar e registrar os resultados positivos do trabalho, explicitando as 
ações e estratégias que ajudaram a potencializar as aprendizagens dos estudantes. Precisavam indicar, também, os desafios que enfrentaram nesse processo, as dificuldades encontradas na operacionalização da proposta e as angústias. Em seguida, elegeram, entre os PEI do grupo (aplicados individualmente), aquele que melhor representou os pontos destacados para a apresentação de um pôster, guiado por um roteiro específico, que serviu para sistematizar os resultados do próprio Eixo e proporcionar a troca e reflexão entre as turmas.

O momento final culminou no aprimoramento do PEI iniciado na primeira semana do Eixo a fim de organizar os elementos teóricos e práticos apresentados; as sugestões para a sua prática pedagógica, incluídas em cada uma das atividades realizadas; e a elaboração de um Memorial Final, contendo as reflexões sobre o seu papel no desenvolvimento do PEI, como possibilidade de contribuição para a construção de uma cultura mais democrática e inclusiva no espaço escolar.

Diante de todas essas atividades realizadas, vale ressaltar que os procedimentos metodológicos utilizados tiveram como ponto de partida e de chegada os fundamentos da abordagem CCS permitindo que todos refletissem sobre as resistências da escola às mudanças exigidas pela abertura incondicional à diversidade e às diferenças. Ao final do Eixo, foi criado um espaço de análise da própria atuação profissional, usando como ponto análise a abordagem CCS, e o Trabalho com Projetos no uso de TDIC.

$\mathrm{O}$ instrumento de coleta, seleção e análise de dados é a plataforma do Ambiente Virtual de Aprendizagem (AVA) TelEduc, onde as ferramentas de interação: diário de bordo, portfólio, fórum, correio e chat servem como base para análise de conteúdo publicado em cada fase. A análise dos dados referentes às três turmas selecionadas para a pesquisa será realizada a partir da consulta aos registros no ambiente (interação nos fóruns de discussão), atividades publicadas no portfólio individual e dos 
grupos, criatividade e criticidade na elaboração dos materiais solicitados, além da própria autoavaliação (questionários diagnósticos e memoriais reflexivos).

Para uma melhor análise dos conteúdos será utilizado o software DSC, que analisa o Discurso do Sujeito Coletivo, tendo como referência as narrativas escritas no AVA, uma vez que este permite organizar, articular e materializar o pensamento de forma a ser possível refletir, rever, revisar, aprofundar e perceber o que se necessita analisar (RINALDI, 2009).

\section{Considerações e perspectivas}

No momento a pesquisa caracteriza-se pela transição do acompanhamento do processo de formação para a análise das narrativas publicadas no AVA e os registros das atividades realizadas nas disciplinas, pensando no produto final, qual seja, a configuração do processo de formação vivenciado e as implicações da mesma para a prática docente. A análise dos conteúdos pedagógicos e tecnológicos e do processo de formação como um todo poderá oportunizar ações que cheguem até a melhoria do ensino público, uma vez que procurou-se potencializar as habilidades e competências dos professores, colocando-os diante de um contexto inclusivo.

Concomitante ao processo de formação semipresencial no curso de Licenciatura em Pedagogia Univesp/Unesp, realizase também a formação de vinte e nove (29) professores do Atendimento Educacional Especializado da rede municipal da Secretaria de Educação de Araçatuba (SP). Esse processo 
de intervenção, também articulado ao grupo de pesquisa de origem, é realizado por meio da apresentação dos mesmos conteúdos do Eixo Articulador e os resultados são registrados por meio de questionários diagnósticos e avaliativos e portfólios de registro. O intuito dessa formação é ampliar as discussões sobre a abordagem CCS e o trabalho com projetos usando as TDIC, enriquecendo o corpus que configurará a organização final da investigação, ou seja, essa formação serve para respaldar a formação inicial e nela são levantados os principais elementos importantes para o processo de formação semipresencial.

Com isso, foi possível compreender as reais necessidades formativas dos professores das quais destacam-se: revisão dos métodos de ensino baseados na instrução e no uso da tecnologia como fim e não como meio (perceberam que o trabalho em uma abordagem CCS demandaria outro olhar sobre a prática docente); organização de atividades didático-pedagógicas usando tecnologias, voltadas ao público-alvo que atendem (não necessariamente seguindo o currículo estabelecido por ano/série, mas atendendo às reais necessidades dos estudantes com deficiência e/ou ditos "normais"); desenvolvimento de materiais didáticos e tecnologias específicas para o público-alvo que atendem; exploração de repositórios educacionais digitais de forma a compreender os pontos importantes desses recursos para a sua própria prática; revisão dos processos de avaliação, compreendendo não somente o que é avaliação formativa, mas colocando-a em prática; entre outros aspectos específicos dessas necessidades destacadas. Assim, a partir dos confrontos e conflitos vivenciados no início da formação, pode-ser averiguar que o problema era especificamente com relação à compreensão do EPAEE e da inserção de TDIC no processo de ensino, além de trabalhar em uma abordagem CCS.

A prévia triangulação dos dados coletados e selecionados já sinaliza para a compreensão das contribuições efetivas da 
formação inicial proposta e por isso está em andamento a análise da matriz curricular do curso, além da análise sobre os resultados de um possível programa de observação que poderá ser realizado junto a pelo menos dois professores formados na perspectiva oferecida.

No desenvolvimento do eixo, foi possível verificar os limites e possibilidades que o Eixo Articulador proporcionou aos professores, no sentido de uma formação que tenha fornecido de fato estratégias pedagógicas para o uso das TDIC como recursos educacionais que devem ser apropriados tanto por parte dos professores, quanto dos estudantes, para o processo de ensino e aprendizagem inclusivo e o desenvolvimento do currículo, demonstrando a importância de não desejar apenas teorizar sobre o processo de inclusão, mas construir novos fazeres pedagógicos para incluir.

A análise preliminar dos resultados indica que, na formação, já foi possível detectar que - embora os professores já compreendam que é necessário: pensar na construção de um currículo mais globalizado; elaborar planejamentos de ensino inclusivo; usar TDIC tais como Objetos Educacionais e outros no processo de ensino; entre outros - ainda não sabem como fazêlo, ou seja, encontram problemas na execução dessas mudanças, uma vez que sua maior dificuldade é saber como articular os conhecimentos construídos no processo de formação e os recursos oferecidos, à sua prática.

Os orientadores de disciplina (tutores) das turmas de Assis, Araçatuba e São José do Rio Preto apontam questões importantes para a organização da análise, como: produção de materiais táteis, voltados à inclusão de estudantes com deficiência visual, nos PEI; os professores tornaram multiplicadores nas escolas em que atuam, formando seus colegas para o uso de Objetos Educacionais; os professores que atuam como coordenadores pedagógicos utilizaram as estratégias de uso 
dos Objetos Educacionais, produziram materiais; um grupo de professores produziu artigo científico usando o referencial teórico e metodológico abordado no Eixo, entre outros aspectos destacados; foi ampliado o debate sobre adaptações curriculares e estratégias de ensino para os EPAEE; os grupos elaboraram PEI em perspectivas transdisciplinares, utilizando como enfoque temas transversais como cultura afrodescendente, diversidade e outros.

Os depoimentos retratam que, para tornar esse processo de formação ainda mais contextualizado, o Eixo Articulador pode ser organizado por meio do estudo de casos, em que os professores poderiam trazer os casos de sua realidade escolar e pedir sugestões ao grupo para desenvolver potencialidades em cada uma das realidades, considerando nesse processo a elaboração e execução dos PEI.

Considerando esses e outros aspectos inerentes à formação, a pesquisa poderá auxiliar na elaboração de programas de formação inicial que atente para a execução de conteúdos pedagógicos e tecnológicos que oportunizem a melhoria do ensino, procurando utilizar as próprias habilidades e competências dos futuros professores para que atuem em contextos inclusivos. Além disso, nasce uma perspectiva de formação construcionista, contextualizada e significativa.

Construcionista no sentido de que o professor aprenda a usar a tecnologia (apropriando-se dos recursos como processadores de textos, gráficos, bancos de dados, simulações, sites, blogs, ferramentas de comunicação, ferramentas de colaboração, repositórios para compartilhar conteúdo digital, acesso a informações e pessoas); aprenda com as tecnologias, usandoas como recursos para sistematizar suas reflexões, analisando as reações dos estudantes, compartilhando experiências, frequentando cursos ou lendo livros; e ensine com a tecnologia, conhecendo o processo de aprendizagem e sabendo, não 
somente usar a tecnologia, mas aplicando-a em seu contexto, como opção de acessibilidade e democratização do ensino para todos.

Contextualizada no sentido de que o professor possa construir o conhecimento sobre as situações problemas que vivencia, transformando-se e transformando o seu contexto em uma relação dialética entre o interpsicológico e o intrapsicológico (VYGOTSKY, 1989). Assim, pode considerar os elementos próprios do seu contexto para a configuração de um pensamento globalizado sobre os temas emergentes em educação, e transformar a sua prática em pesquisa.

E Significativa ${ }^{12}$, em que o professor consiga estabelecer uma relação entre a vida real do estudante que atende aos conceitos pedagógicos estudados, e considere também que o estudante tem interesses próprios e também pode construir conhecimento sobre a sua própria realidade.

\section{Referências}

ALMEIDA, Maria Elisabeth. Educação, Projetos, Tecnologia e Conhecimento. São Paulo: Proem, 2001.

. Informática e formação de professores. Brasília: Ministério da Educação/MEC, 1999.

ARAÚJO, Ulisses Ferreira. Temas transversais e a estratégia de projetos. São Paulo: Moderna, 2003. (Coleção Cotidiano Escolar).

BRASIL. Constituição da República Federativa do Brasil. 10. ed. Brasília, DF: Senado, 1988. 
DELORS, Jacques (Coord.). Educação: um tesouro a descobrir. Relatório para a UNESCO da Comissão Internacional sobre Educação para o século XXI. Porto: Edições Asa, 1999.

DESLANDES, Suely Ferreira et al. Pesquisa Social: Teoria, Método e Criatividade. Petrópolis/RJ: Vozes, 1994.

DODGE, Bernis. WebQuests: a technique for Internet-based learning. The Distance Educator, San Diego, v. 1, n. 2, p. 10-13, Summer 1995.

FIGUEIREDO, Rita Vieira. Políticas de inclusão: escola gestão da aprendizagem na diversidade. In: ROSA, Dalva E. Gonçalves; SOUZA, Vanilton C. Políticas organizativas e curriculares, educação inclusiva e formação de professores. Rio de Janeiro: DP\&A, 2002.

GARCÍA, Carlos Marcelo. A formação de professores: novas perspectivas baseadas na investigação sobre o pensamento do professor. In: NÓVOA, Antonio (Coord.). Os professores e a sua formação. Lisboa: Dom Quixote, 1992.p. 51-76.

GATTI, Bernadete Angelina. Formação de professores e carreira: problemas e movimentos de renovação. 2. ed. Campinas, SP: Autores Associados, 2000. (Coleção Formação de Professores).

IMBERNÓN, Francisco. Formação docente e profissional: formar-se para a mudança e a incerteza. São Paulo: Cortez, 2000.

KNOWLES, J. G.; COLE, A. L.; PRESSWOOD, C. S. Through preservice teachers eyes: experiences through narrative and inquiry. New York: McMilan, 1994.

LÉVY, Pierre. As tecnologias da inteligência: o futuro do pensamento na era da informática. Rio de Janeiro: 34, 1993.

Cibercultura. Tradução de Carlos Irineu da Costa. São Paulo: 34,2000 . 
MANTOAN, Maria Teresa Egler. A integração de pessoas com deficiência: contribuições para uma reflexão sobre o tema. São Paulo: Memnon: Editora Senac, 1997.

. Ensinando a turma toda: as diferenças na escola. Pátio: revista pedagógica. Porto Alegre: ARTMED, ano 5, n. 20, fev./abr. 2002.

MIZUKAMI, Maria da Graça Nicoletti et al. Escola e aprendizagem da docência: processos de investigação e formação. São Carlos: EdUFSCar, 2003.

MORAES, Maria Candida. Educar na biologia do amor e da solidariedade. Petrópolis, RJ: Vozes, 2003.

O paradigma educacional emergente. Campinas, SP: Papyrus, 1997.

Pensamento eco-sistêmico: educação, aprendizagem e cidadania no século XXI. Petrópolis, RJ: Vozes, 2004.

MORAN, José Manuel. Mudanças na comunicação pessoal: gerenciamento integrado da comunicação pessoal, social e tecnológica. São Paulo: Paulinas, 1998.

; MASETTO, Marcos T.; BEHRENS, Marilda A. Novas tecnologias e mediação pedagógica. Campinas, SP: Papirus, 2000.

NÓVOA, Antonio. Relação escola sociedade: novas respostas para um velho problema. In: SERBINO, R. V. et al. (Orgs.). Formação de Professores. São Paulo: Fundação Editora da Unesp, 1998. (Seminários e Debates).

PAPERT, Seymour. Constructionism: A New Opportunity for Elementary Science Education. A Proposal to the National Science Foundation, Massachusetts Institute of Technology, Media Laboratory, Epistemology and Learning Group. Cambridge, Massachusetts, 1986. 
PÉREZ GÓMEZ, Alberto. O pensamento prático do professor: a formação do profissional como profissional reflexivo. In: NOVÓA, A. Os professores e a sua formação. Lisboa: Dom Quixote, 1992.

RINALDI, Renata Portela. Desenvolvimento profissional de formadores em exercício: contribuições de um programa online. 2009. Tese (Doutorado em Educação) - Universidade Federal de São Carlos, São Carlos, 2009.

SCHLÜNZEN, Elisa Tomoe Moriya. A Tecnologia para inclusão de Pessoas com Necessidades Especiais (PNE). In: PELLANDA, Nize Maria Campos; SCHLÜNZEN, Elisa Tomoe Moriya; SCHLÜNZEN JUNIOR, Klaus (Orgs.). Inclusão Digital: Tecendo Redes Afetivas/Cognitivas. 1. ed. Rio de Janeiro: DP\&A, 2005. p. 195-210. v. 1.

Mudanças nas práticas pedagógicas do professor: criando um ambiente construcionista contextualizado e significativo para crianças com necessidades especiais físicas. Tese (Doutorado), Pontifícia Universidade Católica de São Paulo, São Paulo, 2000.

SCHÖN, Donald Alan. The reflective practitioner: how professionals think in action. New York: Basic Books, 1983.

STENGERS, Isabelle. Quem Tem Medo da Ciência? São Paulo: Siciliano, 1990.

TARDIF, Maurice. Saberes profissionais dos professores e conhecimentos universitários. Revista Brasileira de Educação, n. 13. Campinas: Autores Associados, 2000.

; LESSARD, Claude. Trabalho Docente: elementos para uma teoria da docência como profissão de interações humanas. Petrópolis/ RJ: Vozes, 2005.

VALENTE, José Armando. Informática na Educação: Instrucionismo x Construcionismo. Manuscrito não publicado, Núcleo de Informática 
Aplicada à Educação (Nied), Universidade Estadual de Campinas, 1997.

. Liberando a mente: Computadores na Educação Especial. Campinas: Gráfica da Unicamp, 1991.

(Org.). O Computador na sociedade do conhecimento.

Campinas: Gráfica da Unicamp, 1999.

VYGOTSKY, LEV S. A formação social da mente: o desenvolvimento dos processos psicológicos superiores. 3. ed. São Paulo: Martins Fontes, 1989. (Coleção Psicologia e Pedagogia Nova Série).

ZABALA, Antoni. A prática educativa. Porto Alegre: Artmed, 1998.

ZARDO, Sinara Pollom et al. A educação especial na perspectiva da inclusão escolar: altas habilidades/superdotação. 1. ed. Fortaleza/CE: Universidade Federal do Ceará, 2010.

ZEICHNER, Kenneth M. A Formação Reflexiva dos Professores: idéias e práticas. Lisboa: Educa, 1993. 


\section{Notas}

${ }^{1}$ Pesquisa premiada no VII Simpósio Internacional de Informática Educativa, realizado em Leiria/Portugal no ano de 2005, selecionado entre as dez melhores pesquisas do mundo na área de Informática Educativa, publicada pela editora Springer Science/Londres (SANTOS, Danielle Aparecida do Nascimento; SCHLÜNZEN, Elisa Tomoe Moriya. Use of ICT and Project Work in Teacher Training at the Public School System. In: MENDES, António José et al. Computers and Education: Towards Educational Change and Innovation. London: Springer-Verlag London Limited, 2008).

${ }^{2}$ Moraes (1997, p. 31) apresenta o conceito de paradigma à luz de Kuhn, definindo-o como referente à "[...] modelo, padrões compartilhados que permitem a explicação de certos aspectos da realidade. É mais do que uma teoria; implica uma estrutura que gera novas teorias. É algo que estaria no início das teorias."

${ }^{3}$ A Política Nacional de Educação Especial na Perspectiva da Educação Inclusiva (2008) tem como objetivo o acesso, a participação e a aprendizagem dos estudantes público-alvo da educação especial: com deficiência, transtornos globais do desenvolvimento e altas habilidades/ superdotação nas escolas regulares.

${ }^{4}$ Seymour Papert (1986) implementou a linguagem de programação Logo que consiste em criar situações que permite criar comandos e regras caracterizadas por uma sintaxe e uma estrutura em uma sequência lógica de ações de forma que o computador entenda.

${ }^{5}$ Esse ambiente foi desenvolvido pela pesquisadora no processo de formação de professoras da Associação de Assistência à Criança Deficiente (AACD) para o uso de computador com estudantes com deficiências intelectuais e físicas.

${ }^{6}$ O Programa de Expansão do Ensino Superior Público no Estado de São Paulo por meio da Universidade Virtual do Estado de São Paulo (Univesp), organizada pelas três universidades paulistas, USP, Unicamp e Unesp, o Centro Estadual de Ensino Tecnológico Paula Souza (CEETEPS) e a Fundação Padre Anchieta (FPA), oferece cursos na modalidade semipresencial. $\mathrm{O}$ foco desta pesquisa é o curso de Licenciatura em Pedagogia da Unesp/Univesp oferecido nas suas 23 unidades ( $1^{\text {a }}$ turma) de março de 2010 a julho de 2013. 
${ }^{7}$ Os Eixos Articuladores são entendidos no curso como centros geradores onde são trabalhadas as teorias e as práticas educativas em conformidade com as disciplinas desenvolvidas. Tem duração de 90 a 120 horas/aula e foram distribuídos em semanas entre as disciplinas da matriz curricular comum.

${ }^{8}$ Protocolo Aprovado CAAE: 02395412.2.0000.5402.

${ }^{9}$ Nesse momento os estudantes do curso já realizaram o Eixo Articulador: Educação Inclusiva e Especial e Didática de Libras. A média final do Eixo representou 50\% do somatório que compos a média final da disciplina D24 - Didática de Libras.

${ }^{10} \mathrm{O}$ endereço de acesso ao AVA no portal é: $<$ www.edutec.unesp.br $>$. Acesso em: 5 fev. 2013.

${ }^{11} \mathrm{O}$ objetivo desse Objeto de Aprendizagem é construir um álbum de fotografias, resgatando elementos da vivência dos estudantes.

${ }^{12}$ De acordo com a Teoria da Aprendizagem Significativa, de David Ausubel (1968), a aprendizagem significativa ocorre quando o banco de informações no plano mental se revela por meio da aprendizagem por descoberta e por recepção, ou seja, por meio do significado que é atribuído a essa recepção. 